\title{
Covert Treatment in a Cross-Cultural Setting
}

\author{
Neil Pickering
}

\subsection{Introduction}

In the course of the narrative case in this chapter, the ethical question of the use of covert treatment (CT) arises. The parents of a young man (Arjun) have brought him for a consultation with a psychiatrist. The family are from India, but live and work in the UK. The parents have concerns that Arjun has had recurrence of a mental illness, but Arjun refuses to accept this. Rather, he believes that his path and that planned for him by his parents have diverged.

The parents believe that CT may be a solution to the problem that has arisen and relate how Arjun's previous mental health issues were treated in this way, while they were visiting India some years before. The psychiatrist-herself from Indiarefuses to consider CT for Arjun, citing the local (UK) law. Yet she is torn at least in the sense that her previous experience in India has also shown that CT can be successful, and she fears for Arjun's future without medication. She is also aware of cultural influences on the ethical assessment of CT.

The story is invented but based on published cases [1-3]. The psychiatrist is from India where she trained and first practiced.

\subsection{Narrative History}

Arjun comes in with his mother and father. It's my first consultation with them and I invite them all to sit at my desk. Arjun seems to prefer to stand, somewhat in the background from my perspective. His parents are neatly dressed, business people (it turns out). They are all of Indian descent-as am I. The three of them moved to the UK from New Delhi 15 years previously. I observe Arjun while his mother and

\footnotetext{
N. Pickering $(\bowtie)$

Bioethics Centre, University of Otago, Dunedin, New Zealand

(C) The Author(s) 2021

D. Stoyanov et al. (eds.), International Perspectives in Values-Based Mental

Health Practice, https://doi.org/10.1007/978-3-030-47852-0_30
} 
father talk. He is dressed in casual jeans-slightly dirty looking and torn-a newish t-shirt, and old trainers. He is distinctly unkempt, unshaven, and his teeth look like they could do with a clean. I briefly reflect on my own appearance-much more like the parents' than the son's.

"So, how can I help?" I ask. His father tells me that he and his wife are very worried about Arjun.

"Until about 6 months ago, he seemed to be doing very well-he was studying for an MBA at college. Or so we thought. He is a very bright boy. Then suddenly, we found he had stopped studying 3 months before! We didn't notice anything at the time. We're very busy, we run an import-export business, and we're at work all hours."

"He won't talk to us, Doctor" says Arjun's mother.

"He is our only child" says his father, "and we plan for him to join us in the business. We have spent many thousands of dollars on his education. He has done well-top grades at school and as an undergraduate. But now ..." his voice trails off.

I ask if I can speak to Arjun on his own. "I don't know if you'll get anything much out of him" says his mother as she and her husband leave.

It does take some time to get Arjun's attention, and even then he doesn't seem keen to talk about his health.

"Look, I'm fine" he says eventually. "I just lost interest in my studies, that's all. It happens, right? It was all about business and finance and stuff. But that's all very material, isn't it? Now I'm studying the soul."

"Your parents are worried" I venture.

"That's their soul-you see!" he says. "They're tied up in the details of the world-the material things. They think there's something wrong with me-because I have communications with other souls. But it's not my fault they're deaf to the soul-world."

Now he's talking, he's quite voluble. A picture emerges of a person who has auditory hallucinations - these souls he says he talks to. And he seems to have some delusions related to them, though they're all fairly harmless in themselves. Except, just occasionally as Arjun continues, there's something paranoid_- "souls can read souls" he says, a little darkly. "Nothing can be hidden in the soul-verse."

After around 15 min, I invite his parents back in and Arjun goes out for a smoke.

"Well," I say cautiously, "I'd need to see him for longer to be sure, but in my judgement he's hearing voices and he's got some minor delusions. There's just a touch of paranoia."

"Can you give him something, doctor?" asks Arjun's father. "Something to get him back on track."

"Not without his consent" I reply.

"We've tried that" says his father. "He doesn't even see there's anything wrong with him."

"When we were visiting India about 6 or 7 years ago" says Arjun's mother "they gave him something - he didn't know"

"Was he unwell then, too?" I ask. 
"Yes," says the father, "it was before he went to university, and we took him on a trip back to New Delhi; he suddenly started talking to himself all the time, and he got a bit aggressive with his mother. But he wouldn't accept help-just like now. Well, my wife's uncle is a doctor in that part of India, and he suggested giving him some medicine in his tea. He was back to normal in no time."

I hesitate-covert medication was something that I'd used in India myself, before I came to the UK. But its use was a matter of lively debate. What about individual choice? Well-there was scepticism about the sort of Western bioethical ideas that we'd all heard of-autonomy, individual patient rights, and so on. Fine in a rich country like the UK. Anyway, wasn't Indian society characterised by a sense of family and community? A debate on the same lines was going on in the Indian psychiatry journals at that very time [4]. Sometimes, family comes firstthat this was our Indian heritage, our culture. Individualism and bioethics principles based on it were foreign. In the actual case where I used covert treatment, it'd seemed to work-in not dissimilar circumstances to those of Arjun. The patient was a young woman who had been training to be a teacher; suddenly, she'd said she'd been told to take a different path-but some anti-psychotics in her food had sorted all that out.

"I can't support giving him medicine without his agreement," I said after a moment. "You can't do that here-it's against the law. We'll have to try and persuade him he needs help."

"Good luck with that" Arjun's father says bitterly.

Arjun re-joins us, but after some conversation, where I give my professional view, he is clearly not budging. "Look, I'm moving on" he says.

"You'll be moving out" says his father, "if you don't sort yourself out."

"Whatever" replies Arjun.

Where might this be going? Parents getting more and more worried, rows about Arjun not paying his way, doing something with his life; him pushing back. He'll perhaps end up leaving home-couch surfing, at least until his friends get sick of him? Meanwhile, his untreated state of mind is likely to deteriorate. And then .... The uncle in India — when they were on holiday there - he acted quickly, sorting out Arjun's first psychotic episode. Set him on track for a place in the community. But Arjun's trajectory here in the UK is likely to be rather different-into social isolation, a life in fragments. It's not certain, of course: but it's a good bet. What would really be wrong with giving him the help he needs but won't ask for-now, before he ends up in the system, before he estranges his family and friends? Isn't that what I'm here for? True, at this stage, he's able to decide for himself-yet even now, when the delusions are still harmless enough, isn't he already not himself? And what of the family-of which he is a part, which has brought him up? Isn't that an important and real part of the picture?

"So, what do we do now?" asks Arjun's mother, with desperation in her voice.

The only response I have is to advise them to keep talking to him, persuading him, helping him see what's happening. "Make another appointment, for two weeks' time" I say. As I usher them out, my next patient is waiting. 


\subsection{Values Arising in This Story}

In the following analysis, at first, a general assessment of the values at play will be given, before the focus falls on CT and the legitimacy of the value differences at play.

Value-Based Medicine (VBM) focuses on the values in play in narratives where there are differences of view about what to do. We can take values in the wide sense of what matters or is important to those concerned in the story. Two features are strongly expressed in the narrative:

1. Value of education and study, the ethic of work

2. Value of individual freedom-self-expression

(These two values also link to others-see below.)

The first of these - the value placed in education, study and work-is explicitly stated by Arjun's parents. One can imagine that the psychiatrist implicitly endorses these values too. But Arjun implicitly endorses the value of individual freedom-of choosing a path for himself, one different to that his parents have embraced and have desired for him. These two values, of education, study and work, and individual expression, while they do not necessarily conflict with one another, have in the narrative become a focus of difference and disagreement.

A number of other values can also be found in the narrative-some of these are clearly related in various ways to the first two. These include:

3. Value of family — of continuing a line, perhaps of giving back, building the future

4. Value of independence-of being able to support oneself, and ultimately give back

5. Value of social acceptance and social connectedness-having friends, a place in the society, and the fear of isolation

6. Value of appearance-how you present yourself (with associated values of neatness, cleanliness and so on)

7. Value of culture - of what matters to a group, which ties it back to its roots, which it can appeal to

8. Value of health - as an enabler of other things or as a value in itself

9. Value of mental stability and coherence, capacity to decide, perhaps relatedly, authenticity and identity

10. Value of autonomy-conceived abstractly as an expression of an individual's capacity to make authentic decisions and his or her right to be free

11. The values of beneficence and non-maleficence which (like autonomy) are abstracted conceptions, in this case capturing concerns about people's well-being

12. The overt values of a profession, such as the profession of psychiatry (which may vary in different cultural contexts) but might include: patient centred care, least restrictive methods of treatment, restoring health and preventing ill health 
Some of these values are part of the background-they are values against which paths and states of human lives can be gauged, including ones against which a person's health can be judged. Others seem perhaps to be more in the foreground, setting the problems by which the immediate situation is characterized. Some values seem to unite and some seem to divide-and this includes concrete values around day-to-day appearance and behavior, as well as the more abstract ideas such as the value of work, or of finding one's own way, discussed earlier.

\subsection{Covert Treatment (CT)}

Briefly, CT can be defined as treating someone in such a way as to deliberately prevent them from knowing that they are being treated. There is a substantial but quite fragmented literature on this practice (see further reading).

\subsection{Cultural Values and CT}

Cultural values can be identified as those shared by and transmitted through groups of people. In the sense of a set or sets of shared (group) beliefs and values, which play an explicit or implicit guiding role in their behavior, everyone has a culture or cultures.

Relatedly, in the literature on CT-especially in its use with those with mental health problems - a cultural divide has been identified. There are cultures where the focus is more on the family or community, and where CT may be seen as justified for mental health problems, and cultures where the focus is more on the autonomy of the individual, and where CT for mental health may not be seen as acceptable $[5,6]$.

Arjun's family's request for CT may well be associated with the values perspective of their Indian culture. This perspective-sometimes generalized even further to 'the East' - is often presented as being focused on family and community, to which the individual is said (descriptively) to be subordinate.

In an Indian family life, one's individuality is subordinated to collective solidarity, and one's ego is submerged into the collective ego of the family and one's community. Consequently, when a problem-financial, medical, psychiatric, or whatever-affects an individual, it affects the entire family. ... [7]

This should be taken in a slightly more radical way than simply that the family is affected by the illness of one of its members. Arjun's family expect Arjun to share their plans for him; and these plans reflect the continuity of the family's shared identity inter alia in the business they run. Arjun's illness has effects on the family through its impact on these shared plans, and not only through the parents' concern for him as an individual suffering from a disease. 
This has significant normative implications for the individual:

It is expected for an individual to stay part of the family and of the community, the individual will submit to communal norms and will not deviate to an extent where it becomes necessary for the deviant to be ostracized. ... [7]

Given this background, CT may seem sometimes to be justified. This justification may not be (as it might appear to 'western' eyes) merely a rationalization of an imposition of conformity, or paternalism. Rather, it may be a means by which the ostracism of an individual can be avoided, where avoiding this is justified by the perceived significance of group membership to individuals.

On the other hand, individual autonomy can be conceived (in traditional and abstract bioethical terms) as an achievement and right (as in the right to respect for autonomy). In this form, autonomy has become foundational in contemporary 'Western' bioethics. From this 'Western' perspective, it is natural to assume that respect for Arjun's autonomy is the key guiding value in the story.

The adherence to individualistic notions of autonomy may lead to CT being seen as fundamentally an insult to the self-determination of individuals. Indeed, it has been argued that it is inherently self-defeating to deploy CT to attempt to treat someone with a psychiatric problem, since the aim of treatment is to return autonomy to an individual person. This aim is fundamentally undermined by a method that relies on taking autonomy away [8].

\subsection{Cultural Values and Value-Based Medicine (VBM)}

VBM invites us to attend to the values that may underlie disagreement and tensions amongst people and between health professionals and their patients and patients' families.

These differences of values are explicitly recognised in the multiperspective principle of VBM:

In VBM, conflicts of values are resolved primarily, not by reference to a rule that prescribes a "right" outcome but by processes designed to support a balance of legitimately different perspectives ... [9].

The use of the term 'legitimate' here suggests that there are criteria for distinguishing legitimately different from nonlegitimately different values perspectives. But this is misleading - in fact the scope of legitimate value differences is the same as the scope of value differences.

That our values are not only different but legitimately different also follows analytically from the separation of fact and value (or, more exactly, of description and evaluation) insisted on by "nondescriptivism" in philosophical value theory [9].

The argument is that different value perspectives are legitimately different because there is not necessarily a right value perspective. In contrast, in cases of 
differences over facts (description) one can assume that there is a right description, and there are means for moving to consensus. For example, doctors and families might disagree about whether a particular drug can help the patient or not-but a consensus is in principle achievable (e.g. by trying the patient on the drug). But an ethical disagreement about whether CT is an acceptable approach to treatment may represent an irresolvable dissensus.

However, the narrative is set in within the wider UK cultural context. The setting does seem to give a particular weight to the values supporting the individual's rights as against those of the group. Indeed, it might be said that this value is so widely shared in the UK that it would fall under the category of a value that is rightly supported by regulation [9].

\subsection{Transcultural Ethical Perspective}

The transcultural approach to ethics [10] seeks to challenge a simplistic assumption of cultural homogeneity.

There has been a tendency amongst anthropologists, for example, to exaggerate and emphasize cultural difference, constructing cultures as 'radical others'. One assumption underlying the notion that cultures represent 'radical others' is that cultures are homogeneous, having, for example, a single mind set (or mentality). In contrast, transcultural approaches draw attention to the internal variety of cultures and the resulting complexity of commonalities and differences between cultures.

For example, the widely cited contrast between communalistic/family oriented cultures and individualistically oriented cultures might be thought to underlie and determine different attitudes to CT in those cultures. But, within a culture, the relationship of the individual to the wider group may be discussed and perhaps contested, and the claims of both may be explored and questioned.

In the UK, this internal variability presents itself through the significance placed on decision-making competence. This is the site of a fundamental disagreement, about whether and to what extent a poor decision (as judged by community standards) is systematically linked to faulty decision making processes, that is to decision making incompetence. What hangs on this judgement is the point at which the individual loses authority over his or her own decisions.

While there is no space to go into the detail about the disagreements on this point, the heterogeneity at issue is most obviously expressed in the contending views taken on what is called asymmetry. Asymmetry is the view that while a person may have the capacity to choose to accept a treatment that the same person may simultaneously lack the capacity to refuse the very same treatment. Asymmetry in effect provides a means by which autonomy may be limited to those whose choice conforms to that expected by or approved by society.

But asymmetry is not accepted by all. Within the UK, there is a significant division of opinion, suggesting variability rather than homogeneity of values or at least of the weight to be placed upon values. 


\subsection{Conclusions}

VBM supports the idea that differing value perspectives are inherently worthy of consideration - that they are legitimate.

Transcultural ethics tends to offer support for the legitimacy of different value perspectives. It recognises, for example, that within a culture there may be significant variability. As a result, a practice, such as CT, can become the focus of considerable debate within a cultural group, as well as cross-culturally.

In the UK, however, a dominant value - that of individual autonomy-receives strong legal support. In view of this, the case for CT for Arjun doesn't seem to have cultural legitimacy. It is ruled out, whatever the values may be that support it.

Yet, even in the UK, the value of autonomy may be tempered through the mechanism of capacity assessment. In the UK, competence is a central judgement. It is related to the potential harmfulness of a person's choice through the idea of asymmetry. CT for mental health patients may not seem to be a legitimate option in the UK. However, the urge, expressed by Arjun's parents and psychiatrist, to prevent any further decline in his health and avoid a feared future of social isolation is also expressed in the malleability of capacity judgements.

Acknowledgements My grateful thanks to the editors of this volume, Taryn Knox, attendees at the 2018 INPP Conference (Hong Kong) and Bioethics Centre seminar (2019), and the members of the Bioethics Centre Postgraduate Forum, all of whom commented on various earlier versions of this paper.

\subsection{Guide to Further Sources}

In addition to the Indian Journal of Psychiatry issue [4] and [1-3, 5, 6, 8], a case discussion of CT was published in the Asian Bioethics Review (Pickering NJ. (ed.) 2013. Case Scenario 2: Covert Treatment of Violent Patients. Asian Bioethics Review 5(3):198-223). For articles on Transcultural approaches to ethics see [10] and the other articles in that special edition of the Kennedy Institute Journal of Ethics.

\section{References}

1. Khurshid KA. A tale of two cities. Am J Psychiatry. 2006;163(8):1335-6.

2. Wong JGWS, Poon Y, Hui EC. Clinical ethics "I can put the medicine in his soup, Doctor!". J Med Ethics. 2005;31:262-5. https://doi.org/10.1136/jme.2003.007336.

3. Kala AK. Covert medication; the last option: a case for taking it out of the closet and using it selectively. Indian J Psychiatry. 2012;54(3):257-65. https://doi.org/10.4103 /0019-5545.102427. PMCID: PMC3512364.

4. Sathyanarayana Rao TS, Kallilvayalil RA, Andrade C, Kala AK, Antony JT, Murthy RS, Sarin A, Ramachandran P, Rangaswamy T, Srinivasan N, Srinivasan T. Editorial and Special Theme. Indian J Psychiatry. 2012;54(3):203-5, 257-79. 
5. Srinivasan T, Thara R. At issue: management of medication noncompliance in schizophrenia by families in India. Schizophr Bull. 2002;28:531-5.

6. Stroup S, Swartz M, Appelbaum P. Concealed medicines for people with schizophrenia: a U.S perspective. Schizophr Bull. 2002;28:537-42.

7. Laungani P. Mental illness in India and Britain: theory and practice. Med Law. 1997;16:509-40.

8. Aherne L, van Tosh L. Taking issue: the irreversible damage caused by surreptitious prescribing. Psychiatr Serv. 2005;56:383.

9. Fulford, KWM (2009) Facts/Values: Ten Principles of Values-Based Medicine . In Radden J (ed.) The Philosophy of Psychiatry: A Companion Published to Oxford Scholarship Online: January 2009 https://doi.org/10.1093/acprof:oso/9780195149531.001.0001. https://doi. org/10.1093/acprof:oso/9780195149531.003.0017.

10. Nie J-B, Fitzgerald RP. Connecting the east and the west, the local and the universal: the methodological elements of a transcultural approach to bioethics. Kennedy Inst Ethics J. 2016;26(3):219-47.

Open Access This chapter is licensed under the terms of the Creative Commons Attribution 4.0 International License (http://creativecommons.org/licenses/by/4.0/), which permits use, sharing, adaptation, distribution and reproduction in any medium or format, as long as you give appropriate credit to the original author(s) and the source, provide a link to the Creative Commons license and indicate if changes were made.

The images or other third party material in this chapter are included in the chapter's Creative Commons license, unless indicated otherwise in a credit line to the material. If material is not included in the chapter's Creative Commons license and your intended use is not permitted by statutory regulation or exceeds the permitted use, you will need to obtain permission directly from the copyright holder. 